\title{
Design of a Non Fragile Optimal Controller Realization for Vehicle Suspension System for Different Road Profiles
}

\author{
M. Abid Saeed ${ }^{1}$, Niaz $\mathrm{Ali}^{2}$, Muhammad Waqas ${ }^{3}$, Anees ur rehman ${ }^{3}$ \\ ${ }^{1}$ Sarhad University of Science and Information Technology, Peshawar, Pakistan \\ ${ }^{2}$ National Power Control Center, NPCC, Pakistan \\ ${ }^{3}$ Sarhad University of Science and Information Technology, Peshawar, Pakistan
}

\begin{abstract}
This paper explains a suspension system of a vehicle which comprises of spring mass and damper. The main objective is to design a proper controller that can damp oscillations in order to provide safety, ease and comfort to passengers of vehicle during uneven road surface, bumps and small patches. To perform the desired task state space model of a quarter wheel vehicle suspension system is derived. The response of the system is simulated in MATLAB/SIMULINK. The open loop response showed that the derived model is stable. Different types of controllers are designed i.e. Linear Quadratic Regulator (LQR) and Observer based controller to analyze the system in closed loop. Both the controllers showed improved performance for different road profiles. It is observed and shown that observer based controller has better response than Linear Quadratic Regulator (LQR) controller. Simulink models for Linear Quadratic Regulator $(L Q R)$ and observer based controller are designed. Besides, different types of realization techniques (minimal realization, balanced realization, modal realization, observer canonical realization) are compared for minimum fragility in controller implementation. The difference among the different realization controllers has been analyzed in detail for rounding off error or truncation error and an optimal non fragile controller design has been presented. Different disturbances were imposed upon the simulated model. All the results are analyzed in open and closed loops. The closed loop response showed that the oscillations were damped quickly and the desire results were achieved successfully.
\end{abstract}

Keywords: Suspension system, optimal control, realization, non-fragile

\section{Introduction}

A mechanical system that connects the wheels of a vehicle to the main body in such a way that passengers feel minimum effects of jolts and jerks while driving on rough and uneven road surface, The suspension system greatly concern with automobile's ease, performance and safety. Among the properties of a good vehicle suspension system it must has suitable road handling ability [1-3]. For designing a suspension system, it is difficult to keep at the same time in view a high standard of ride and road handling ability under all driving circumstances [4-5]. The difficulties shootout from the extensive range of operational conditions created by varying road situations, vehicle speed and load due to passengers increase and decrease in numbers [6-7].

A suspension system is basically designed to give pleasure, safety and ride comfort to passengers and driver inside the cabin of a vehicle. The complete mathematical derivations for the quarter vehicle model in state space form are simulated in MATLAB/SIMULINK [8].The block diagram of vehicle model is shown in Fig.1.

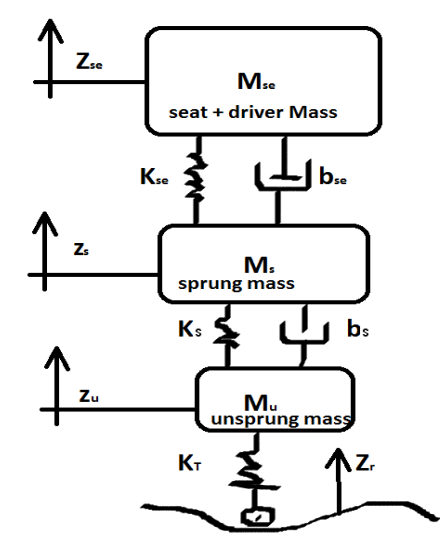

Fig. 1: Block Diagram of a Vehicle suspension system 


\section{Mathematical Model of Vehicle Suspension System}

State space model of vehicle suspension system is derived as given in [9],

$$
\begin{aligned}
& Z_{g e}=V_{s e} \\
& z_{s}=V_{s} \\
& Z_{u}=V_{u}
\end{aligned}
$$

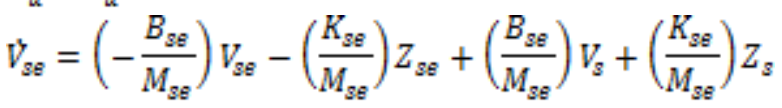

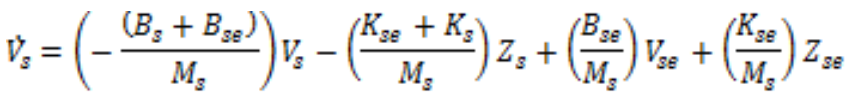

$$
\begin{aligned}
& +\left(\frac{B_{s}}{M_{s}}\right) V_{u}+\left(\frac{R_{s}}{M_{s}}\right) Z_{u} \\
& V_{u}=\left(-\frac{B_{g}}{M_{u}}\right) V_{u}-\left(\frac{K_{g}+K_{u}}{M_{u}}\right) Z_{u}+\left(\frac{B_{g}}{M_{u}}\right) V_{s}+\left(\frac{K_{g}}{M_{u}}\right) z_{g}+\left(\frac{K_{u}}{M_{u}}\right) z_{r}
\end{aligned}
$$

Here,

Zse $\quad=\quad$ Driver seat displacement

$\mathrm{Zs} \quad=\quad$ Sprung mass seat displacement

$\mathrm{Zu} \quad=\quad$ Unsprung mass seat displacement

Vse $\quad=\quad$ Driver seat velocity

Vs $=$ Sprung mass seat velocity

$\mathrm{U} \quad=\quad$ Unsprung mass seat velocity

Let's defining numerical parameters for designed model,

Mse $\quad=120 \mathrm{~kg} \quad$ Mse $=$ Seat and driver mass

Ms $\quad=2500 \mathrm{~kg} \quad$ Ms $=$ Sprung mass

$\mathrm{Mu} \quad=320 \mathrm{~kg} \quad \mathrm{Mu}=$ Un sprung mass

Bse $\quad=350 \mathrm{Ns} / \mathrm{m} \quad$ Bse $=$ Damping coefficient of the seat suspension

Bs $\quad=1500 \mathrm{Ns} / \mathrm{m} \quad \mathrm{Bs}=$ Damping coefficient of the vehicle suspension

$\mathrm{Kt} \quad=125000 \mathrm{~N} / \mathrm{m} \quad \mathrm{Kt}=$ Tire stiffness

$\mathrm{Ks} \quad=28000 \mathrm{~N} / \mathrm{m} \quad \mathrm{Ks}=$ Vehicle suspension spring stiffness

Kse $\quad=8000 \mathrm{~N} / \mathrm{m} \quad$ Kse $=$ seat suspension spring stiffness

$\mathrm{Zr} \quad=0.22 \mathrm{~m} \quad \mathrm{Zr}=$ Road input

\section{Methodology}

Open loop response showed that the designed system was stable but the performance was not satisfactory. Different types of controllers were designed i.e. LQR (linear quadratic regulator) and observer based controller to overcome the disturbing effects and to improve the performance parameters. Further, these controllers are tested for different road profiles. Different realization techniques are used to obtain a reduced and non-fragile model. Later on, both the controllers are also compared.

\subsection{Simulink Model}

First the model in open loop is simulated in Simulink software as shown in Fig. 2.

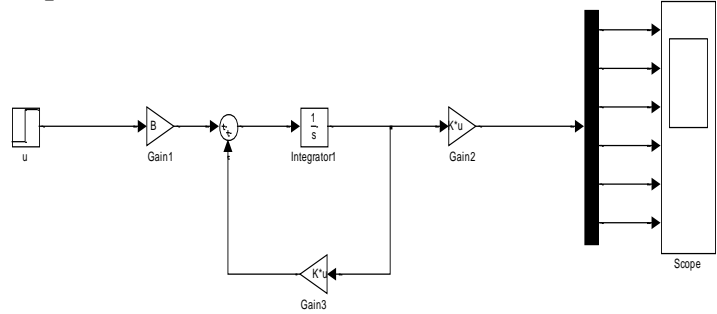

Fig. 2: Simulink model for open loop system

Then, to optimize the designed model LQR controller gain $\mathrm{K}$ is obtained and added to Simulink model. Fig.3 represent LQR model. 


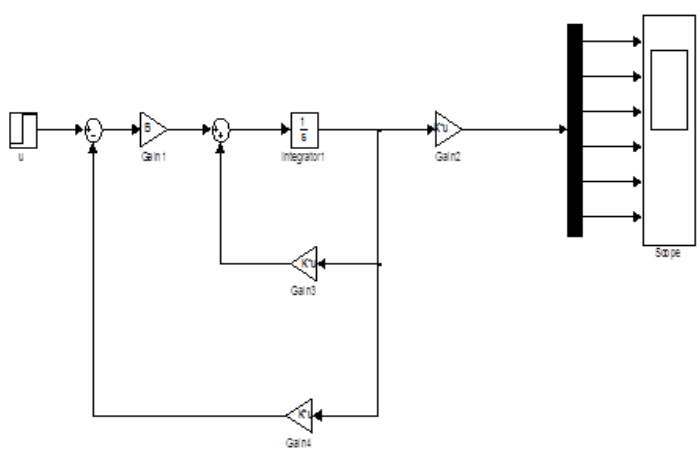

Fig.3: Simulink model for LQR controller

For observer based controller the observer gain "L" is estimated by pole placement techniques. Fig.4 shows observer based controller model.

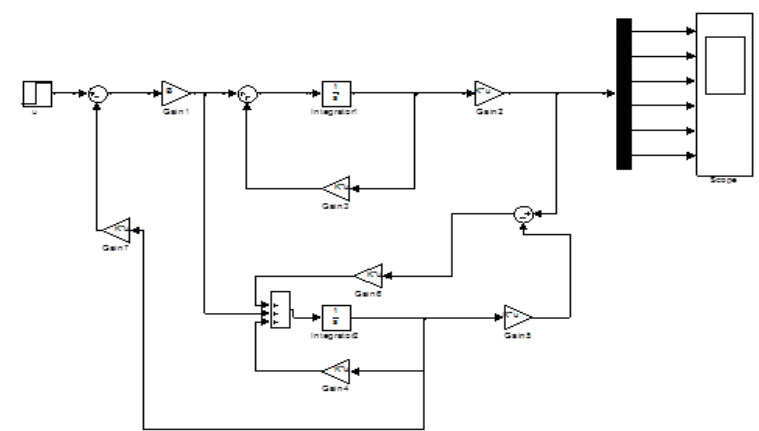

Fig. 4: Simulink model for observer based controller

The difference between above two Simulink models is find out and simulated in Simulink as shown in Fig.5.

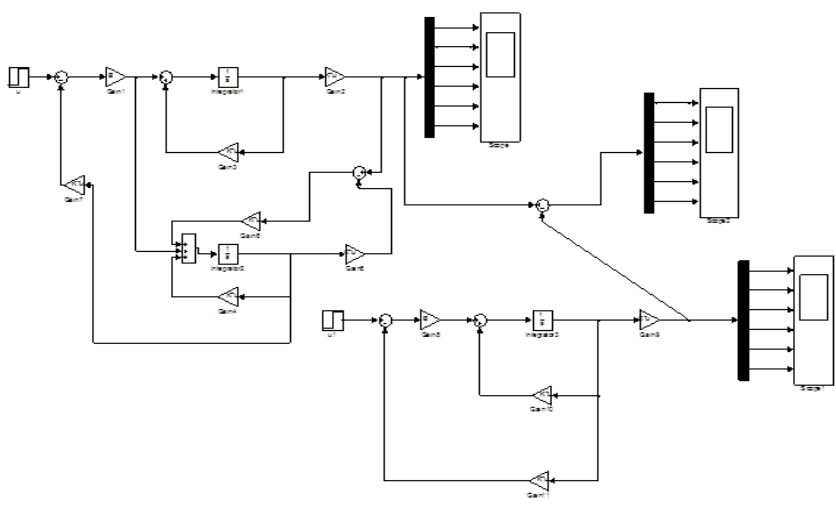

Fig.5: Simulink model for comparison of two controllers

In addition, these controllers are tested for different road grades i.e. $(0.22 \mathrm{~m}, 0.44 \mathrm{~m} \& 0.66 \mathrm{~m})$ as per the requirements of local Pakistani roads.

\subsection{Realization techniques}

In order to obtain a reduced and non-fragile optimal controller different realization techniques are used. Minimal realization (The realization is known as "minimal" as it defines the system with least number of states) Balanced realization, Modal realization and Observer based canonical realization are the other different techniques used to obtained a reduced and non- fragile model.

\section{Results and Conclusion}

This thesis work is carried out on considering a quarter wheel model of a Vehicle suspension system. The mathematical derivations are done in state space form. For simulation MATLAB/SIMULINK software is used. Several road disturbances are being injected to the system. The open loop response in MATLAB shows oscillations, large overshoot and required large settling time to damp. Different controllers/compensators are designed to obtain the desired response. LQR controller improved the performance of the system. The results 
obtained are satisfactory. Then observer based controller is designed. After adding the observer gain to observer based controller the performance of the system is improved significantly as compared to LQR. Different realization techniques are then used, by applying these techniques the controllers action is made more efficient and the system is made highly stable and non-fragile.

4.1 Open Loop response
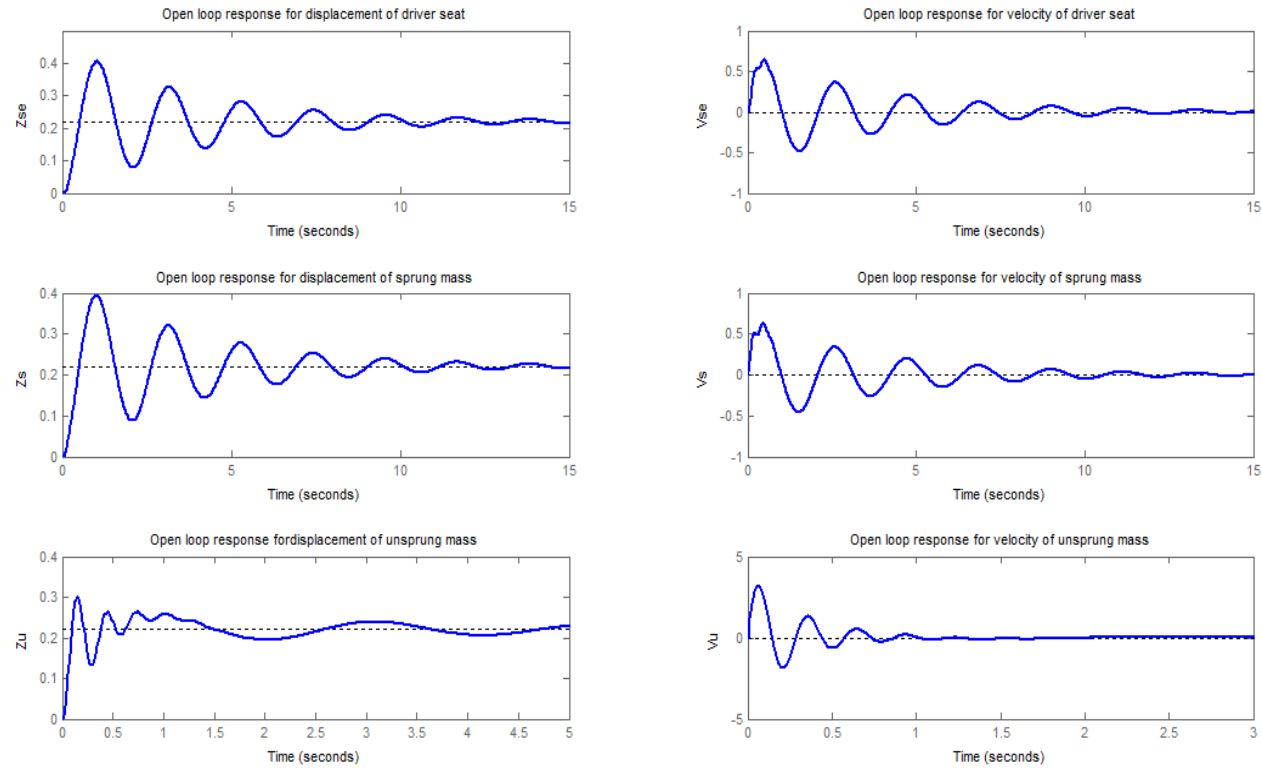

Fig. 6: Open Loop Step response

The open loop response shows the following:

Table I: Open Loop Response analysis

\begin{tabular}{|c|c|c|}
\hline Description & Response & Response \\
\hline \multirow{2}{*}{ Driver Seat } & $\%$ Overshoot & $80 \%$ \\
\cline { 2 - 3 } & Settling Time & $20 \mathrm{sec}$ \\
\hline \multirow{2}{*}{ Sprung Mass } & $\%$ Overshoot & $60 \%$ \\
\cline { 2 - 3 } & Settling Time & $20 \mathrm{sec}$ \\
\hline \multirow{2}{*}{ Un Sprung Mass } & $\%$ Overshoot & $300 \%$ \\
\cline { 2 - 3 } & Settling Time & $5 \mathrm{sec}$ \\
\hline
\end{tabular}

Thus the open loop response is very uncomfortable for the passengers.

\subsection{LQR Controller response}
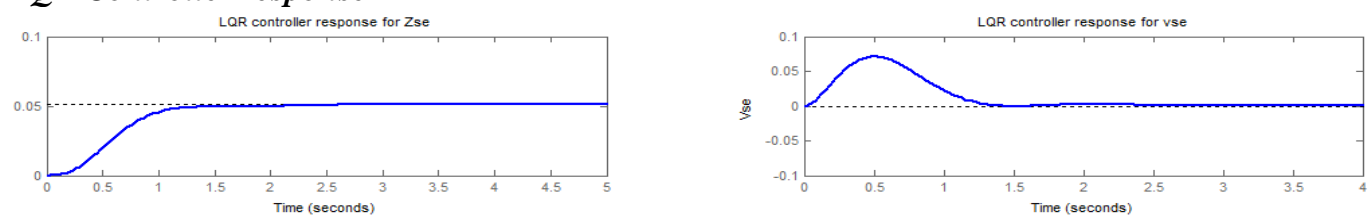

LQR controller response for Zs
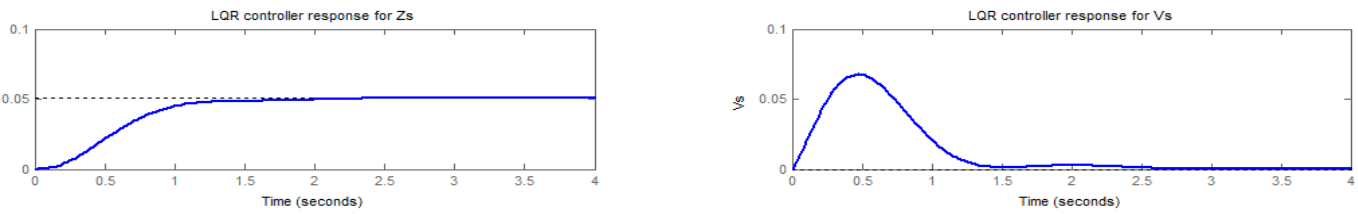

LQR controller response for Zu
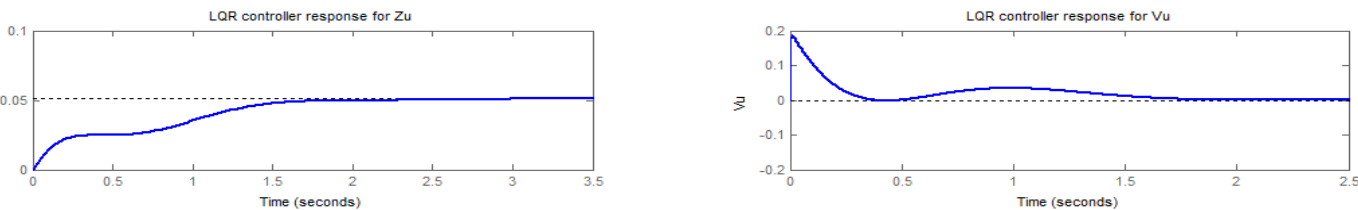

Fig 7: LQR Controller Response 
The closed loop response showed in Table II.

Table II: LQR controller Response analysis

\begin{tabular}{|c|c|c|c|}
\hline \multirow{2}{*}{ Description } & Response & $\begin{array}{c}\text { Open } \\
\text { Loop }\end{array}$ & LQR Controller \\
\hline \multirow{2}{*}{ Driver Seat } & $\%$ Overshoot & $80 \%$ & $8 \%$ \\
\cline { 2 - 4 } & Settling Time & $20 \mathrm{sec}$ & $3 \mathrm{sec}$ \\
\hline \multirow{2}{*}{ Sprung Mass } & $\%$ Overshoot & $60 \%$ & $6 \%$ \\
\cline { 2 - 4 } & Settling Time & $20 \mathrm{sec}$ & $3 \mathrm{sec}$ \\
\hline \multirow{2}{*}{ Un Sprung Mass } & $\%$ Overshoot & $300 \%$ & $16 \%$ \\
\cline { 2 - 4 } & Settling Time & $5 \mathrm{sec}$ & $3 \mathrm{sec}$ \\
\hline
\end{tabular}

Thus the LQR Controller gives a better response and settled the oscillations in the vehicle body quickly.

4.3 Observer based controller Response
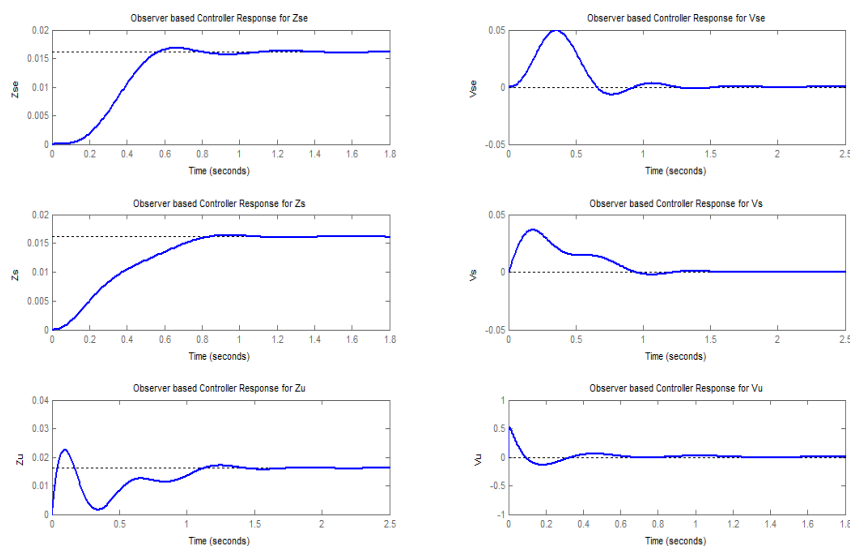

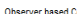

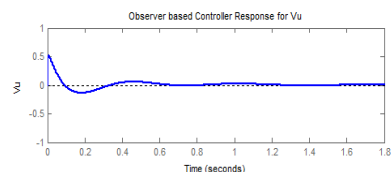

Fig. 8: observer based Controller Response

The closed loop response showed in Table III.

Table III: Observer based controller Response analysis

\begin{tabular}{|c|c|c|c|}
\hline Description & Response & $\begin{array}{c}\text { Open } \\
\text { Loop }\end{array}$ & $\begin{array}{c}\text { Observer based } \\
\text { Controller }\end{array}$ \\
\hline \multirow{2}{*}{ Driver Seat } & $\%$ Overshoot & $80 \%$ & $1.8 \%$ \\
\cline { 2 - 4 } & Settling Time & $20 \mathrm{sec}$ & $1.5 \mathrm{sec}$ \\
\hline \multirow{2}{*}{ Sprung Mass } & $\%$ Overshoot & $60 \%$ & $1.4 \%$ \\
\cline { 2 - 4 } & Settling Time & $20 \mathrm{sec}$ & $1.2 \mathrm{sec}$ \\
\hline \multirow{2}{*}{ Un Sprung Mass } & $\%$ Overshoot & $300 \%$ & $13 \%$ \\
\cline { 2 - 4 } & Settling Time & $5 \mathrm{sec}$ & $1 \mathrm{sec}$ \\
\hline
\end{tabular}

Thus the Observer Based Controller gives a better response and damped the oscillations more quickly.

\subsection{Minimal Realization}

For LQR controller no state has been reduced, the controlled response has six states and after minimal realization the states remain the same. Difference between the LQR controller and minimal realization response is plotted as shown in Fig. 9 

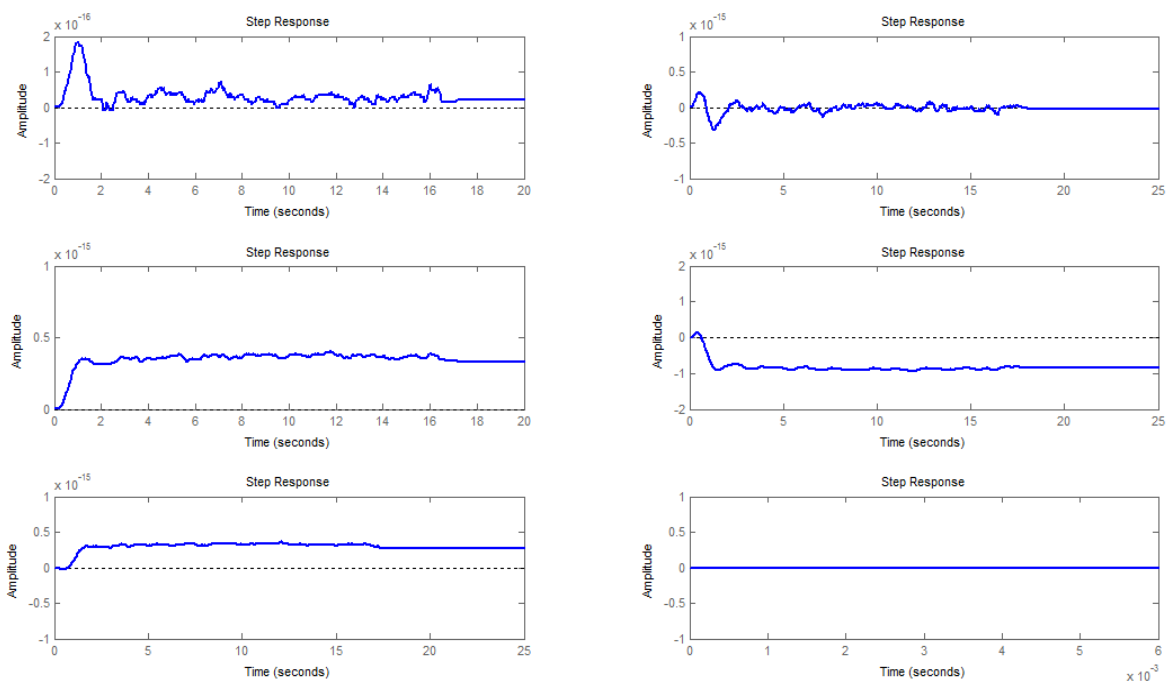

Fig.9: Minimal Realization of LQR controller response

For observer based controller six states have been reduced, the controlled response has twelve states and after minimal realization the states are reduced to six.
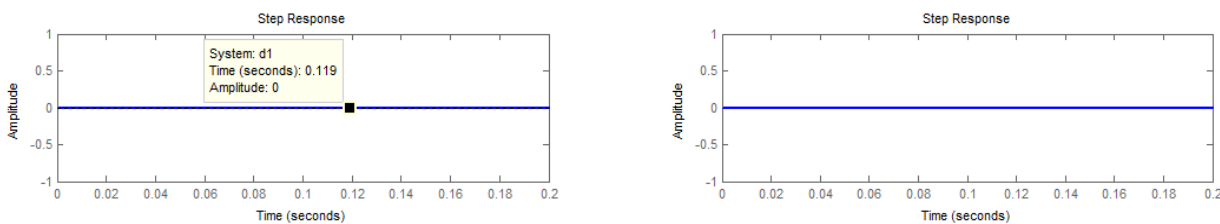

Step Response
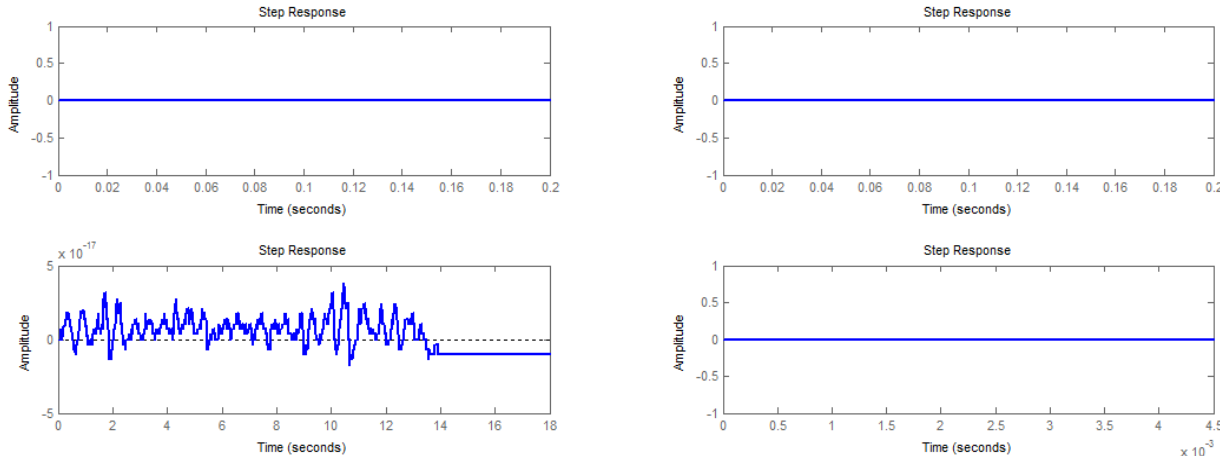

Fig.10: Minimal Realization of observer based controller response

\section{Balanced realization}

Difference between the LQR controller and balanced realization response is plotted as shown in Fig.11.
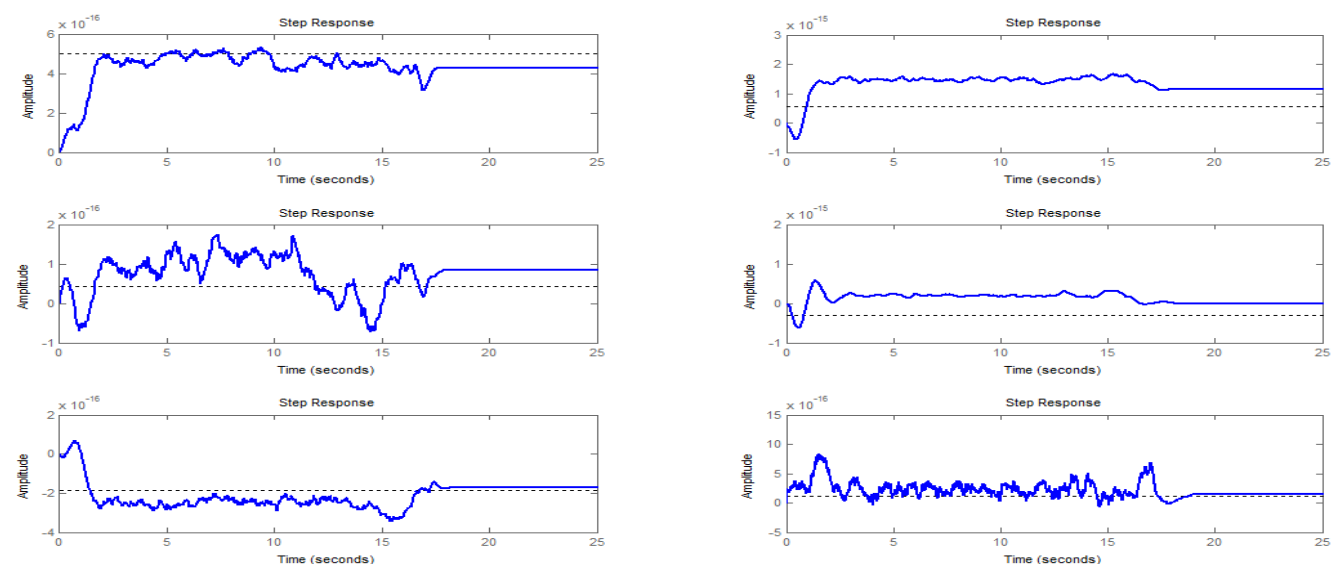

Fig.11: balanced realization of LQR controller response 


\section{Modal realization}

Difference between the LQR controller and modal realization response is plotted as shown in Fig.12
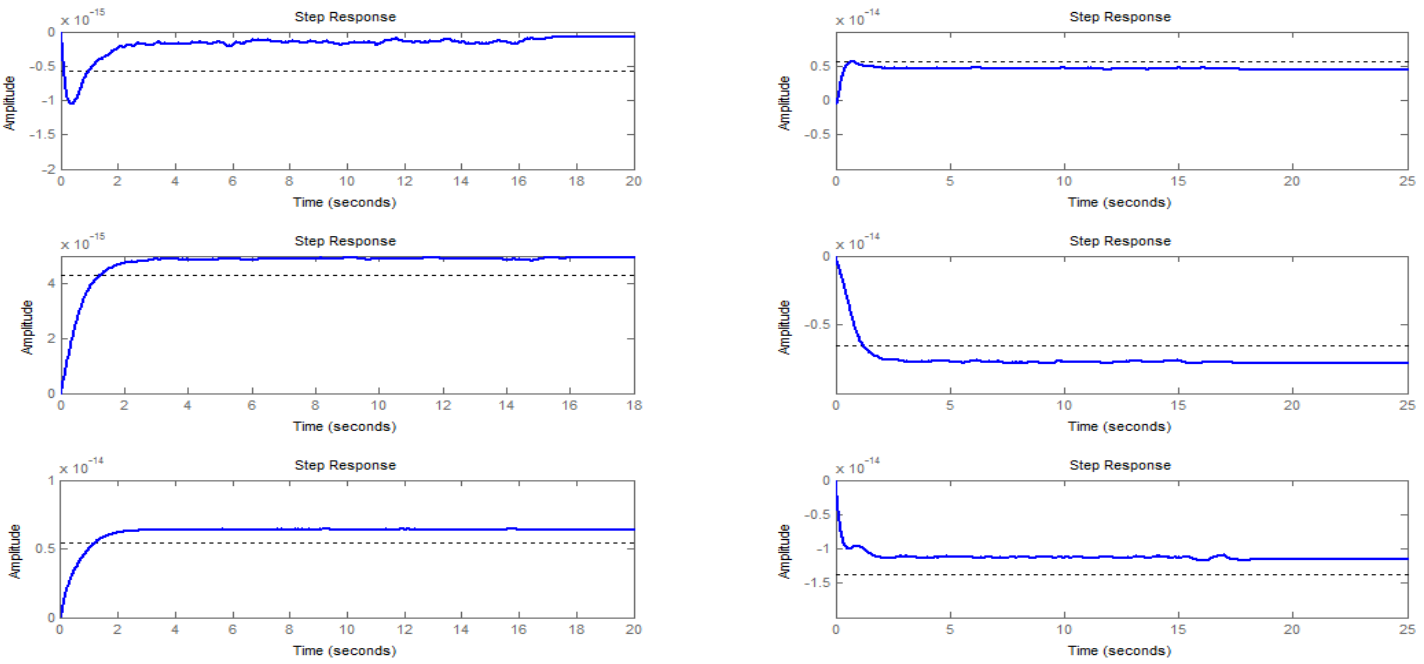

Fig.12: Modal realization of LQR controller response

\section{OBSERVER CANONICAL REALIZATION} in Fig. 13

Difference between the LQR controller and Observer Canonical realized response is plotted as shown
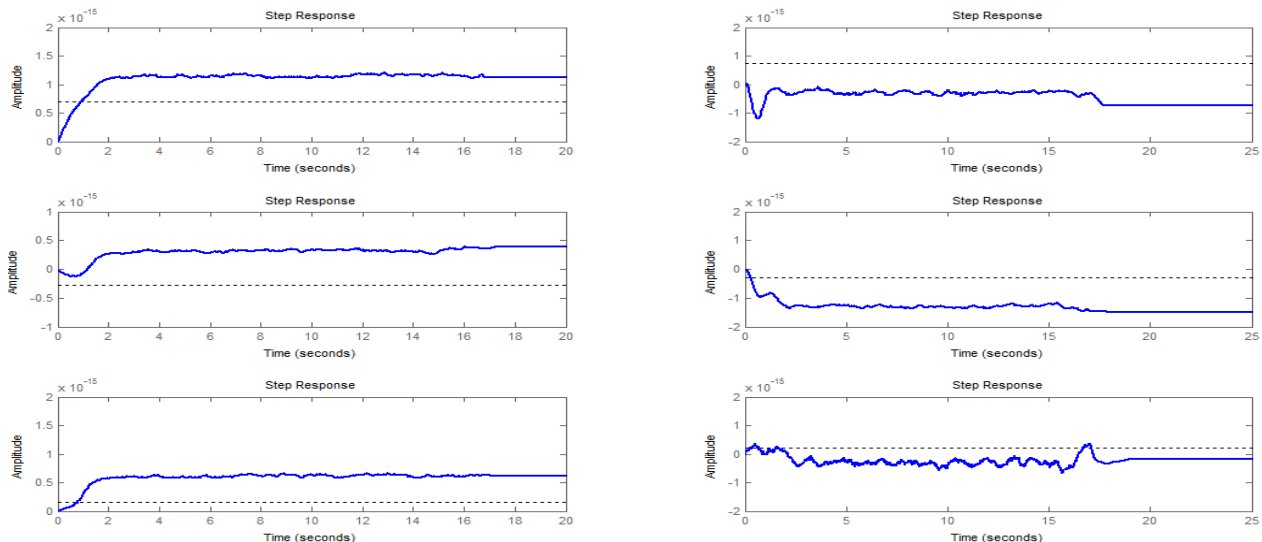

Fig.13: Observer canonical realization of LQR controller response

A brief summary of all types of realization techniques is given below in Table IV. This table shows that minimal realization gives the least error to controller which represents the most optimal and most non-fragile optimal controller technique.

Table IV: Realization analysis for different controllers

\begin{tabular}{|l|c|c|}
\hline Realization type & LQR controller & $\begin{array}{c}\text { Observer based } \\
\text { controller }\end{array}$ \\
\hline Minimal Realization & $10^{-8}$ & $10^{-18}$ \\
\hline Balanced Realization & $10^{-15}$ & $10^{-17}$ \\
\hline Modal Realization & $10^{-14}$ & $10^{-14}$ \\
\hline $\begin{array}{l}\text { Observer canonical } \\
\text { Realization }\end{array}$ & $10^{-15}$ & $10^{-8}$ \\
\hline
\end{tabular}




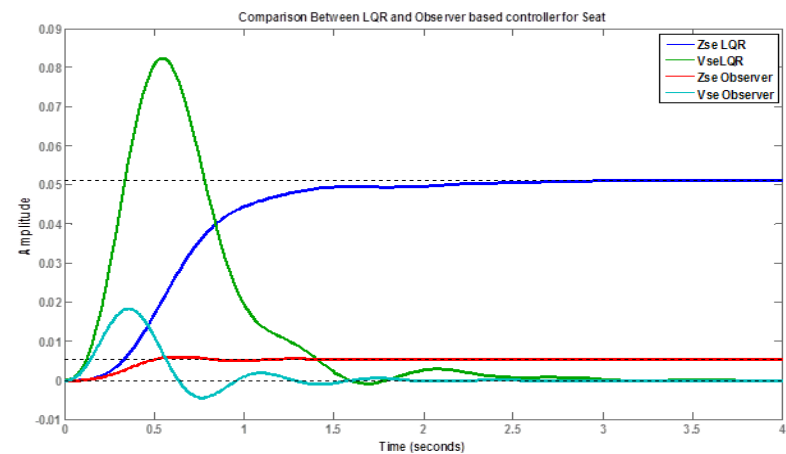

Fig.14: Comparison between the two controllers

From the plot it is very clear that the observer based controller has much better response as compared to the LQR controller. The overshoot and the settling time have been reduced up to a great level for both the displacement and velocity responses.

\subsection{Simulation Results for Disturbances $\mathrm{Zr}=0.44 \mathrm{~m} \& 0.66 \mathrm{~m}$}

Both the controllers are checked for an input disturbance $\mathrm{Zr}=0.22 \mathrm{~m}$, in this portion these controllers are further checked for different disturbances and their responses are analyzed. Closed loop response of the model using LQR Controller is shown for different disturbances in Fig. 15
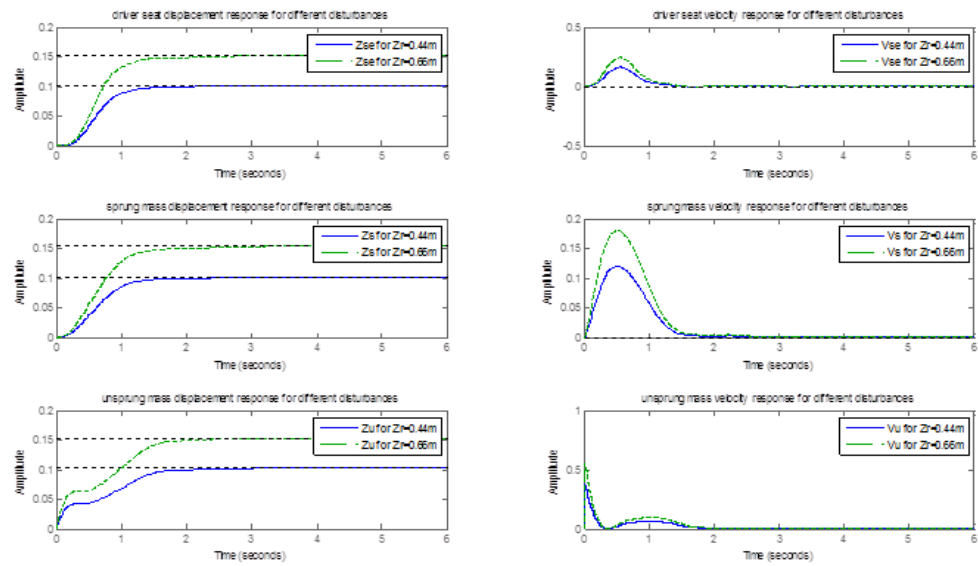

Fig. 15: Simulation Results for Disturbances using LQR

For different input disturbances the LQR controller shows good response. The LQR controller settles the oscillation quickly, reducing the oscillation and overshoot. Thus the designed LQR controller provides good handling ability for wide range of disturbances and provides good ride comfort for passengers. Closed loop response using Observer based controller of the model is shown for different disturbances in Fig. 16
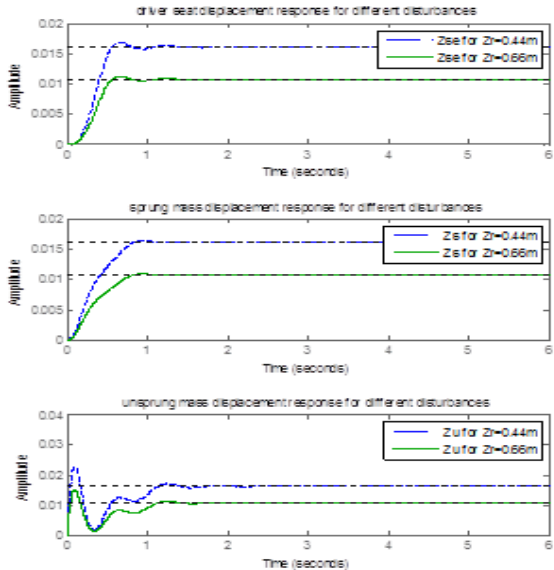
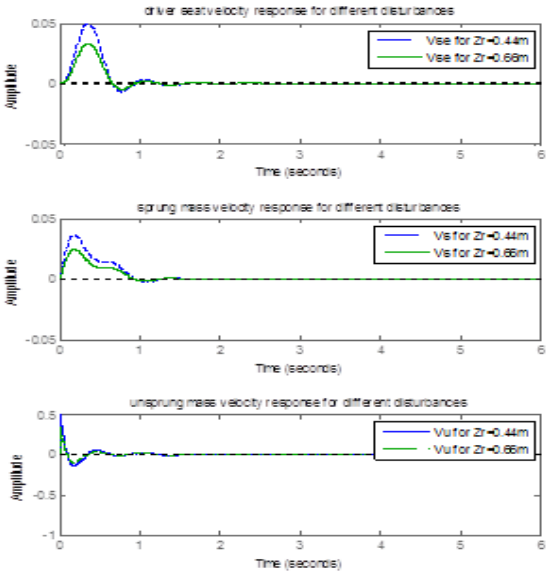

Fig. 16: Simulation Results for Disturbances using Observer based Controller 
For different input disturbances the Observer based controller shows better response. The Observer based controller settles the oscillations more quickly, reducing the oscillation and overshoot. The designed Observer based controller provides better handling ability for wide range of disturbances and provides better ride comfort for passengers. Hence it is very clear from results that the observer based controller shows better response as compared to LQR controller.

\section{References}

[1]. Kowarska, Jarosáaw Skarbek, Krystian Kuczek and Tadeuszuhl, "Model-Based Engineering-Simulations Based Design of the Suspension of City Vehicle", AGH University of Science and Technology Department of Robotics and Mechatronics Mickiewicza, Poland, 2011.

[2]. Tadeo Armenta and Miguel Strefezza, "Controlling Vehicle Suspension Using an Optimal Fuzzy Controller", May 2007.

[3]. A.A.Aldair and W.J.Wang, "Design an Intelligent Controller for Full Vehicle Non Linear Active Suspension System", University of Sussex, UK, 2011.

[4]. Zhou J, Zhou D, Teo KL and Zhao G, "Nonlinear Optimal Feedback Control for Lunar Module Soft Landing", IEEE International Conference on Automation and Logistics, Shenyang, China, IEEE, 2009.

[5]. Nurhan GÜRSEL, İsmail Hakkı ALTAȘ and Levent GÜMÜȘEL, "Fuzzy Control of a VehicleSuspension System", "Intelligent Manufacturing Systems", Sakarya University, Department of Industrial Engineering, May 2006.

[6]. G.Verros and Natsiavas, "Design Optimization of Quarter Car Model with Passive and Semiactive Suspensions Under Random Road Excitation", Aristotle University, Greece, 2005.

[7]. S.D.Senturia, "Micro system Design", New York, 2005.

[8]. Carnegie Mellon, "Control Tutorial for Mat lab", The University of Michigan, 1997.

[9]. D.Blanchard, "On the Control Aspects of Semi-active Suspensions for Automobile Applications", Virginia, 2003. 